\title{
Topic Inclusive Edication In Indian Context: An Appraisal
}

\author{
Dr Mohd Abid siddiqui \\ Associate ProfessorDepartment of EducationA.M.U.,Aligarh, India
}

\section{INCLUSIVE EDUCATION IN INDIAN CONTEXT: AN APPRAISAL}

There are 2.68 crore persons with disabilities in India who constitute 2.21 percent of total population. The percentage of disabled population in rural and urban areas is 2.24 percent and 2.217 percent respectively. This includes persons with visual, hearing, speech, locomotors, mental disabilities and multiple disabilities. The percentage of men with disabilities is 2.41 as against 2.01 in women (Census, 2011). Their literacy level and access to education is much lower as compared to the non-disabled population. The census of India estimated that 51 percent of persons with disability were not literate; 26 percent had received education up to the primary level (five years of schooling); 11 percent up to middle level (eight years of schooling) and only 09 percent had secondary level and above. Interestingly, enrolment ratios for those with disabilities aged 5 to 18 years in a mainstream school were higher in rural areas than in the urban areas (Rao, 2016). Education is a powerful instrument of social change, and often initiates upward movement in the social structure. There by it is essential to provide education to each and every child including differently abled students. It is because of this reason the right of every child to education is proclaimed in the universal declaration of human rights (1948) and was strongly reaffirmed by the World Declaration on Education for All (1990). In June 1994 representatives of 92 governments and 25 international organizations formed the world conference on special needs education, held in Salamanca, Spain. They agreed a dynamic new statement on the education of all disabled children, which called for inclusion to be the norm. The conference adopted a new framework for action, the guiding principle of which is that ordinary schools should accommodate all children, regardless of their physical, intellectual, social, emotional, linguistic or other conditions. All educational policies should stipulate that disabled children attend neighborhood school that would be attended if the child did not have a disability.

The convention on Rights of Persons with Disabilities was adopted by the United Nations General Assembly on 13 December 2006 and came into force on 3 May 2008. As of July 2016, it has 160 signatories and 166 parties, including 165 states and the European Union. The convention aimed at to protect and ensure the full and equal enjoyment of all human rights and fundamental freedom by all persons with disabilities and to promote respect for their inherent dignity. There are eight guiding principles that underlie the convention.

- Respect for inherent dignity, individual autonomy including the freedom to make one's own choices, and independence of persons.

- Non-discrimination.

- Full and effective participation and inclusion in society.

- Respect for difference and acceptance of persons with disabilities as part of human diversity and humanity.

- Equality of opportunity.

- Accessibility.

- Equality between men and women.

- Respect for the evolving capabilities of children in the disabilities and respect for the right of children with disabilities to preserve their identities.

The convention states that persons with disabilities should be guaranteed the right to inclusive education at all levels, regardless of age, without discrimination and on the basis of equal opportunity. In order to implement its policies the convention suggested the state parties to ensure the following

1. Children with disabilities are not excluded from free and compulsory primary education or from secondary education.

2. Adults with disabilities have access to general tertiary education, vocational training, adult education and life long learning.

3. Persons with disabilities receive the necessary support, within the general education system, to facilitate their effective education, and

4. Effective individualized support measures are put in place to maximize academic and social development. 


\section{SHIFTING MODELS OF DISABILITY:}

The four major approaches have been adopted in regard to Persons with Disabilities.

- The Charity mode: This approach gave birth to a model of custodial care, causing extreme isolation and marginalization of people in the disabilities. Unfortunately, in some contemporary practices the reflection of this model can still be traced.

- The Bio-centric Model - This bio-centric model of disability regards disability as a medical and genetic condition. The implication remains that disabled persons and their families should strive for 'normalization' through medical cures and miracles.

- The Functional Model : In this model, a child's right to education is dependent on whether or not the child can access the school and participate in the classroom, rather than becoming accessible to children with disabilities.

- The Human Rights Model: The human rights model positions disability as an important dimension of human culture, and it affirms that all human beings are born with certain inalienable rights. Therefore they should be treated equal and should receive education in inclusive classroom setting. This is the latest approach which is accepted internationally and being considered most appropriate for educating the differently abled persons.

Concept of Inclusive Education: Currently, the term 'inclusion' and 'responsible inclusion' are used to identify the movement to provide services to students with disabilities in general education setting (Smith \& Dowdy, 1998). It is acknowledged that within the context of inclusion some services to students with disabilities may be necessary outside the general class room but all students with disabilities belong with their nondisabled peers. Lamar-Dukes \& Dukes (2005) states that 'the move towards including students with disabilities in general education is fundamentally about the delivery of services in environments where students with disabilities have sufficient and systematic opportunities to engage with students without disabilities'. Inclusive education is both a philosophy and educational practice. Philosophically, inclusive education is based on the right of all children, regardless of ability level, to have access to a quality educational programme. All students came to school with diverse needs and abilities, so no students are fundamentally different. Therefore it is the responsibility of general education system to be responsive to all students. As an educational practice inclusive education obviously attempts to provide equal access to academic instructions and social opportunities for all students.

\section{INDIAN SCENARIO:}

Constitution of India ensures equality, freedom, justice and dignity of all individuals and implicitly mandates an inclusive society for all including persons with disabilities. The Kothari Commission (1964-66), paid attention to education of handicapped children in very clear words and said that the education of the handicapped children should be an inseparable part of Indian education system. The commission recommended experimentation with integrated programmes in order to bring as many children as possible into these programmes.

Until the 1970s, the policy encouraged segregation. Most educators believed that children with physical, sensory, or intellectual disabilities were so different that they could not participate in activities of a common school (Advani, 2002).

National Policy on Education (1986) brought the fundamental issue of equality centre stage. The policy clearly stated that the objective should be to integrate the physically and mentally handicapped with the general community as equal partners, to prepare them for normal growth and to enable them to face life with courage and confidence.

Education of children with disabilities in India, as all over the world, has moved from segregation, special schools to integrated education. There is a national level central government sponsored scheme called Integrated Education of Disabled Children (IEDC). This project was started is 1980s and designed based on the experience gathered from a UNICEF assisted pilot project called Project on Integrated Education of Disabled Children. This is basically an itinerant resource teaching approach and one resource teacher was given to every 8 children with special needs. However, the programme met with little success due to its shortcomings. This programme was revised in 1992. Under the revised scheme, 100 percent assistance became available to schools involved in the 'integration' of students with disabilities. In 1997, IEDC was amalgamated with other major basic education projects like DPEP (Chadha, 2002) and Sarva Shiksha Abhiyan (SSA). The key objective of SSA is universalization of elementary education, the three important aspects of which are access, enrolment and retention of all children in 6-14 years of age. SSA ensures that every child with special needs, irrespective of the kind, category and degree of disability is provided meaningful and quality education. Hence SSA has adopted a zero rejection policy. The goal of UEE has further strengthened by the enactment of the right of children to free and compulsory education act 2009 making free and compulsory education a fundamental right of all the children in the age group of 6-14 years. This amendment has given a new thrust to the education of children with special needs. 
The Government of India has enacted three legislations for persons with disabilities to provide equal opportunities including their socio-economic inclusion in the society.

(i) Rehabilitation Council of India Act, 1992.

(ii) Persons with Disabilities (Equal Opportunities, protection of rights and full participation) Act 1995,

(iii) National Trust for Welfare of Persons with Autism, Cerebral Palsy, Mental Retardation and Multiple Disability Act, 1999.

There are eight national institutes associated with the ministry of social justice and empowerment working for the development of manpower in different parts of India.

National Policy for Persons with Disabilities (2006) recognizes that persons with disabilities are valuable human resources for the country and seeks to create an environment that provides them equal opportunities, protection of their rights and full participation in society. It is in consonance with the basic principles of equality, freedom, justice and dignity for all, including persons with disabilities. The salient features of National Policy for persons with disabilities (2006) are given below

- Physical rehabilitation which includes early detection and intervention, counseling and medical interventions and provisions of aids and appliances.

- Educational rehabilitation which includes vocational training, and

- Economic rehabilitation for dignified life in society.

The Scheme of Inclusive Education for Disabled at Secondary Stage (IEDSS) has been launched from the year 2009-10. This scheme replaces the earlier scheme of Integrated Education for Disabled Children (IEDC) and provides assistance for the inclusive education for the disabled in classes IX-XII. This scheme now subsumed under Rashtriya Madhyamik Shiksha Abhiyan (RMSA) from 2013. Thus initiatives have been taken and due attention is being paid by the Ministry of Social Justice to implement inclusive education in India. Every new initiative leads to many problems and issues in regard to policies, planning, funding, administration and evaluation. Moreover negative attitudes of the different stake holders also pose a big problem. Implementation of the programme with a positive attitude by paying attention to emerging problems and issues and showing genuine desire to address them will definitely yield positive results.

\section{ADVANTAGES OF INCLUSIVE EDUCATION:}

- Inclusive education provides ample opportunity to differently abled students of social interaction with general students and thus assist them to develop social competency among them.

- Students in inclusive setting get the opportunity to imitate socially acceptable behavior of the students without special educational needs.

- It is cost effective and has a wide reach in Indian context. Practically it is not possible to educate children with special education needs in segregated setting.

- The standard of learning is raised in general class room giving the opportunity of high performance to differently abled students.

- They get the opportunity to engage in out of class room activities with general students like an equal partner which further aid to develop psychomotor and affective aspects of the students.

- Inclusive setting is helpful in making differently abled students more confident and well adjusted as they consider equal partner in teaching learning process.

- Expectations of teachers are also raised and they often develop higher standards of performance for students with special education needs.

- Parents of differently abled students feel satisfied and elated by sending them in inclusive schools. Their ecstatic attitude further gives their children healthy and happy home environment which is crucial for their personality development.

- Children without special needs can learn that differently abled students have many positive characteristics and abilities. This will enhance the acceptance level of differently abled students as equal partner in the class room and in turn also in society.

- Inclusion prepares the children to fully participate in a pluralistic society when they are adults.

- Students without special education needs may serve as peer tutors during instructional activities for their differently abled friends.

\section{OBSTACLES IN IMPLEMENTATION OF INCLUSIVE EDUCATION:}

- $\quad$ Although the movement of inclusive education is progressing steadily in its right direction in India but still the true philosophy of inclusion is not understood by various stakeholders associated with it. Lack of 
knowledge of the area is the basic hurdle towards successful and speedy implementation of the inclusive education.

- Government has not made sufficient preparation to implement inclusive education as there is a huge dearth of specially trained teachers needed for the job. It is widely agreed that cooperation and commitment of those directly involved, particularly teacher is very important for successful implementation of inclusive education (Hegarty, 1994; Meijer 2003; Forlin 2010).

- We still lack in any effective mechanism to coordinate and cooperate among all specialists like special education teachers, resource teachers, psychologists, speech and language pathologists, occupational and physical therapists, recreational therapist, audiologist and other service professionals. It is really difficult to obtained desired results in absence of it.

- Success of inclusive education also depends upon availability of an effective resource room support as all needs of differently abled students cannot be met fully in general education classroom. Some may need additional interventions which they can receive in a resource room. Thus lack of resource room facilities is another big problem.

- Attitudes of the students without special education needs prove to be a major barrier in social integration of persons with disabilities. It has been noted that such students suffer from bullying physical or emotional. The negative attitudes often develop due to lack of knowledge. This negative tendency has its root in cultural and religious factors of Indian society.

- It has been reported by the researchers that attitude of the mainstream teachers towards inclusion is also not positive due to insufficient knowledge, exposure, training and support to adopt curriculum. Results of research on teachers working in inclusive setting have demonstrated that they have serious reservations about including students with special education needs in their classroom (Ring \& Travers; Pijl, 2010). Teachers vary significantly in their ability or willingness to make adaptations (Mc Lesky and Waldron, 2002).

- Lack of public support for inclusion: Parents of children without SEN don't want inclusion of children with special education needs in mainstream education. They have fear in their mind that it will lower the standard of education and teachers will pay more attention to these children. Student without special education needs will feel alienated in the classroom leading to distorted personality development.

- Poor infrastructure of our schools is also an impediment towards implementing the inclusive education. The prevailing conditions of majority of government schools are horribly deficient in terms of building, classrooms, toilets, play ground and library facilities. Since most schools are ill equipped to respond to special needs and therefore create hurdle for learners in physically getting into schools. Facilities like ramps, lifts and directional cures are mostly negligible in majority of Indian schools.

- Curricular adaptations are very crucial in implementing the inclusive education to gratify the peculiar needs and requirements of the differently abled learner. Unfortunately we have not done justice to this aspect in its true sense. In absence of curriculum adaptations the inclusive education has no meaning.

- There are also personal barriers which are psychological in nature and related to the personality of the differently abled children like poor self concept, lack of adjustment, shaky confidence and feeling of in security and behavior problems.

- Insufficient planning and preparation to provide orientation to in-service teachers toward inclusive education and its related challenges.

- Lack of ICT equipments and needed expertise to use it also a big issue. Conditions of our schools specially in rural areas are not conducive for its proper use and maintenance also.

- There are serious issues related to governance, policy, planning, financing and implementation as well as monitoring of inclusive education in our country.

- We fail to provide quality education to our students at elementary education level particularly in government schools due to poor infrastructure, lack of teachers and will power of the government. Inclusion of differently schools may further deteriorate the quality of education.

\section{CONCLUSIONS AND SUGGESTIONS}

It is accepted universally that, out of many models of educating the persons with disabilities, adopted so far inclusive education is most feasible and appropriate and based on the principle of human rights to live a dignified life. People with disability face a wide range of barriers such as organizational barriers, attitudinal barriers and knowledge barriers that affect social inclusion. There are strategies to overcome these barriers. It is the school's role to overcome these barriers so that students with disabilities can receive appropriate education with their non-disabled peers. Following are the suggestions for the successful implementation of the inclusive education programme in Indian context

D An extensive programme to make people aware about the philosophy of inclusive education, and knowledge about differently abled students is the dire need of the hour. For this purpose use of mass media, UGC 
sponsored seminars and conferences, involvement of NGOs, publications of relevant research papers in journals and articles in magazines at local, state and national levels is highly essential. Dissemination of knowledge will help change the negative attitudes of all the stake holders.

$>$ Organization of orientation and refresher programmes for the administrators (school principals), in-service teachers, civil servants, local community leaders and medical professionals on inclusive education will be fruitful for effective implementation of the strategies.

$>$ B.Ed. in special education is a programme to train teachers in dealing with students with special education need. All government and private universities and colleges must be encouraged to run this course to help increase the skilled and trained teachers for successful carrying out the inclusive education programme.

$>$ Guidance and counselling of the parents of children with special education needs should be organized in all urban and rural schools to provide sufficient knowledge to handle different abilities of their children and help develop their potential to the maximum limit.

$>$ Religious leaders, social workers and community leaders should be involved to play their positive role in changing the negative attitude of the masses specially in rural areas towards disability. They should be made aware that children with special needs also have the right to receive education and have the potential to excel if provided opportunity.

$>$ We need to implement a universal strategy to create a conducive environment to remove all the physical barriers which create difficulty in access of differently able students. Supportive and encouraging environment need to be created by the administrator and the teaching faculties by engaging all students in different curricular and co-curricular programme.

$>$ There is a need to make compulsory course on disability and pedagogy of teaching for children having special needs to B.Ed. and M.Ed. teachers' training programmes. (Limaya, 2016).

$>$ Policies of the government are quite good but their implementation and monitoring has no vitality. The government needs to take appropriate steps in this direction.

$>$ Implementation of inclusive education is a gigantic task and requires major change in infrastructure, training of teachers and other stake holders as well as curricular adaptations. Huge amount of money will be needed for this task in addition to effective planning and its implementation. Government should provide sufficient financial support to all educational institutions needed for required changes.

\section{REFERENCES}

[1] Smith, T.E.C., Pollow, E.A., Patton, J.R. \& Dowdy, C.A. (2011). Teaching Students With Special Needs In Inclusive Setting, New Jersey: Pearson Education Inc. Pp. 22-25.

[2] Mondal, A. \& Mete, Jayanta (2012). Inclusive Education: Paradigm Shift In Education For Children With Special Needs In India. In Kumar, T. Pradeep (Ed). Innovative Trends In Education, New Delhi: Aph Publishing Corporation

[3] Agrawal, A. \& Singh, Y.P. (2015). "Problems And Prospects Of Inclusive Education In India". Proceedings Of The $3^{\text {rd }}$ Global Summit On Education, Kaula Lampur, Malaysia.

[4] Department Of Education (2000). Sarva Shiksha Abhiyan: A Programme For Universal Elementary Education. New Delhi: Mhrd, Goi.

[5] National Policy For Persons With Disabilities (2006). Government Of India: Ministry Of Social Justice And Empowerment.

[6] Http://Socialjustice.Nic.In/Nppde.Php

[7] Project Integrated Education For Disabled (1993). New Delhi: Ncert.

[8] Uncrpd (2008). Un Convention On The Rights Of Persons With Disabilities.

[9] Www.Un.Org/Disabilities/Default.Asp

[10] Ministry Of Law And Justice (2009). The Right Of Children To Free And Compulsory Act, 2009, New Delhi: Molj, Goi.

[11] Unesco (1994). The Salamanca Statement And Framework For Action, Geneva: Unesco Special Education, Division Of Basic Education.

[12] Http://Www.Csie.Org.Uk/Inclusion/Unesco-Salamanca.Shtml

[13] Dummugudem \& Ramchand, B. (2014). Inclusive Education As Solution To Barriers To Cwsn And Answer For Their Success, International Journal Of Humanities And Social Science Invention, Vol. (3)8, Pp. 43-48.

[14] Norwich, B. \& Avramidis, E. (2002).Teachers' Attitudes Towards Integration/ Inclusion: A Review Of The Literature, European Journal Of Special Needs Education, Routledge, Uk: Taloy \& Francis, Vol. 1792), Pp. 129-147.

[15] Lamar-Dukes, P. \& Dukes, C. (2005). Consider The Role And Responsibilities Of The Inclusion Support Teacher. Intervention, 41(1) 55-59. 
[16] Smith, T.E.C, \& Dowdy, Ca (1998). Educating Young Children With Disabilities Using Responsible Inclusion. Child Education, 74(5), 319-320.

[17] Advani, I. (2002). "Education A Fundamental Right For Every Child Regardless Of Her/His Special Needs". Journal Of Indian Education; Special Issue On Education Of Learners In With Special Education Needs, New Delhi, Ncert

[18] Chadha, A. (2002) Inclusive Education In Dpep Journal Of Indian Education. Special Issue On Education Of Learners In With Special Education Needs, New Delhi, Ncert

[19] Wcefa (1990). Meeting Basic Learning Needs: A Vision For The 1990, New York: The Inter Agency Commission ( Undo, Unesco,Unicef, World Bank)

[20] Pijl, S.J. (2010). "Preparing Teachers For Inclusive Education: Some Reflections From The Netherlands “. Journal Of Research In Special Educational Needs 10(1): 197-201.

[21] Ring, E And Travers, J. (2005).” Barriers To Inclusion”, A Case Study Of A Pupil With Severe Learning Difficulties In Ireland", European Journal Of Special Needs Education 20(1): 41-56.

[22] Meijer, C.J.W (2003). "Special Needs Education Across Europe. Middelfart, Demark: European Agency For Development In Special Needs Education.

[23] Forlin, C. (2010). "Re-Framing Teacher Education For Inclusion", In Teacher Education For Inclusion: Changing Paradigms And Innovative Approaches, Edited By C. Forlin, 3-10. Abingdon: Routledge.

[24] Hegarty, S. (1994). "Integration And The Teacher" In New Perspectives In Special Education: A Six Country Study Of Integration. Edited By Meijer, Pijli And Hegarty, 125-131. London: Routledge

[25] Mc Leskey, J. And Waldron, N.L. (2002). "Inclusion And School Change: Teacher Perceptions Regarding Curricular And Instructional Adaptations". Teacher Education And Special Education. 25(1). 41-54.

[26] Kurniawati, Farida, Boer, A.A.D And Minnert, A.E.M.G. (2014). Characteristics Of Primary Teacher Training Programme On Inclusion: A Literature Focus.”Educational Research. Vol.56 (3).310-326.

[27] Report Of Education Commission (1986). Educational And National Development, Ministry Of Education, Govt. Of India, Ncert, New Delhi

[28] National Policy On Education, (1986). Government Of India (Department Of Education), Ministry Of Human Resource Development, May, 1986.

[29] Limaya, S. (2016). Special Inclusion For Differently-Abled: Issues And Strategies. Yoga.Vol.60

[30] Www.Un.Org $>$ Disabilities $>$ Conservation Full.

[31] Http://Www.Censusindia.Gov.In 